\title{
Human Resource Management Practices and Voluntary Turnover: A Study of Internal Workforce and External Labor Market Contingencies
}

\author{
Joseph A. Schmidt ${ }^{\text {a*}}$, Chelsea R. Willness ${ }^{\mathrm{a}}$, David A. Jones ${ }^{\mathrm{b}}$, and Joshua Bourdage ${ }^{\mathrm{c}}$ \\ ${ }^{a}$ University of Saskatchewan, 25 Campus Drive, Saskatoon, SK, Canada. ${ }^{b}$ University of \\ Vermont, 55 Colchester Ave, Burlington, Vermont, USA. ${ }^{c}$ University of Calgary, 2500 \\ University Drive NW, Calgary, AB, Canada.
}

This is an Accepted Manuscript of an article published by Taylor \& Francis in The International Journal of Human Resource Management on March 30, 2016 (advance online publication), available online: https://doi.org/10.1080/09585192.2016.1165275.

We would like to thank Jennifer Hendry, Calum MacDonald, and Herb Kee for their contributions to questionnaire development, sampling strategy, and oversight of the data collection. This research was funded in part by the Canadian Tourism Human Resource Council and the Social Sciences and Humanities Research Council of Canada (\# 430-2014-00383).

A separate, but overlapping, portion of the dataset used in this research was reported in a previously published study (Pohler and Schmidt, 2015). 


\title{
Human Resource Management Practices and Voluntary Turnover: A Study of Internal Workforce and External Labor Market Contingencies
}

\begin{abstract}
We tested relationships between employee quit rates and two bundles of human resource (HR) practices that reflect the different interests of the two parties involved in the employment relationship. To understand the boundary conditions for these effects, we examined an external contingency proposed to influence the exchange-based effects of HR practices on subsequent quit rates - the local industry-specific unemployment rate — and an internal contingency proposed to shape employees' conceptualization of their exchange relationship - their employment status (i.e., full-time, part-time, and temporary employment). Analyses of lagged data from over 200 Canadian establishments show that inducement HR practices (e.g., extensive benefits) and performance expectation HR practices (e.g., performance-based bonuses) had different effects on quit rates, and the former effect was moderated by unemployment rate. The effects of HR practices on quit rates did not differ between FT and PT employees, but a different pattern of main and interactive effects was found among temporary workers. These findings suggest that employees' exchange-based decisions to leave may be less affected by the number of hours they expect to work each week, and more by the number of weeks they expect to work.
\end{abstract}

Keywords: Strategic human resource management, labor markets, social exchange, economic exchange, employment relationships, voluntary turnover, employment status.

An organization's human capital can be an important source of competitive advantage in an increasingly complex business environment (Crook, Todd, Combs, Woehr, and Ketchen, 
2011). Studies in strategic human resource management (SHRM) show that certain types of HR practices are associated with favorable firm-level outcomes like financial performance (e.g., Huselid, 1995) and operational effectiveness (e.g., Takeuchi, Lepak, Wang, and Takeuchi, 2007). To advance this literature, scholars have called for research to understand the effects of HR practices on more proximal outcomes, like employee turnover, to help explain their more distal effects on firm performance (Kehoe and Wright, 2013). Other researchers recently characterized the relationship between HR practices and employee turnover as an "understudied yet promising" avenue for future research (Posthuma, Campion, Masimova, and Campion, 2013: 1209).

Meta-analytic evidence shows that employee turnover is an important mediator of the effects of HR practices on firms' financial performance (Jiang, Lepak, Hu, and Baer, 2012). Shaw, Delery, Jenkins, and Gupta (1998) observed, however, that SHRM studies have historically focused almost exclusively on explaining overall turnover without distinguishing between voluntary turnover (quit rates) versus involuntary turnover (dismissal rates; e.g., Huselid, 1995). Meta-analyses show that quits, rather than dismissals, drive the effects of overall turnover on organizational performance (Park and Shaw, 2013), and that quits and dismissals differ in their antecedents. Whereas employee dismissals reflect decisions made by organizational authorities, quit rates reflect decisions made by employees. As such, this distinction requires the application of theoretical frameworks aligned with the perspectives of the decision makers involved. Accordingly, we grounded our hypotheses in exchange theory, which has guided many empirical studies on employees' attitudes, behaviors, and decisions — including their decisions to leave (e.g., Shore, Coyle-Shapiro, Chen, and Tetrick, 2009). 
We tested two bundles of HR practices that reflect the interests of each party involved in the exchange-based employment relationship (Tsui, Pearce, Porter, and Tripoli, 1997). Inducement HR practices reflect an employer's long-term investments in employee well-being, thereby motivating employees to maintain their commitment to the employment relationship (e.g., fair treatment and internal promotion practices). Performance expectation HR practices reflect an employer's pursuit of its own interests by incentivizing and maximizing employee performance (e.g., performance-based bonuses). We also used exchange theory to inform our focus on two contingencies that might shape the effects of these two bundles of HR practices.

Our focus on understanding contingency effects reflects the import role that "best fit" perspectives have played in advancing the SHRM literature, and the need to consider both internal and external contingencies to understand the effects of HR practices (Jackson and Schuler, 1995). Indeed, contemporary SHRM research has largely moved beyond testing whether and which HR practices contribute to firm performance by focusing on the processes and associated boundary conditions that shape these effects, such as the industry context, a firm's internal capabilities, and the strategic importance of a firm's human capital. Researchers often ground these and other contingencies in best-fit models and configurational perspectives that tend to focus on the fit between HR practices and a firm's competitive context and strategy (Boxall and Purcell, 2000). Common to these frameworks is a focus on explaining why corporate leaders invest in certain HR practices, or the contexts in which HR practices bring greater financial and performance-related returns. Organization-level quit rates, however, are a function of the decisions and interests of individual employees, which requires a corresponding theoretical lens to understand and study the phenomenon. Theory on employment and exchange relationships is one such theoretical perspective. 
Researchers have tested mostly external contingencies of the effects of HR practices on various firm-level outcomes (e.g., Chadwick, Way, Kerr, and Thacker, 2013), but comparatively few studies have tested contingency effects on quit rates (see Sun, Ayree, and Law, 2007 for an exception). Our study addresses this gap by testing the extent to which local, industry-specific unemployment rates moderate the associations between the HR bundles and quit rates. These tests represent a bridge between "macro" SHRM research and "micro" research on employee turnover in which the external labor market has been shown to be a boundary condition affecting employees' decisions to leave (Hom and Griffeth, 1995). Examining this external contingency has important implications, given the lingering employment instability since the start of the recent global recession (OECD, 2014).

We also test the extent to which the associations between HR bundles and quit rates differ depending on employees' full-time (FT), part-time (PT), or temporary employment status, answering calls for more research on the effects of HR practices in the context of different employment modes (e.g., Conway and Briner, 2002). This, too, has potentially important implications because PT and other contingent employment arrangments are becoming more common (Bidwell, Briscoe, Fernandez-Mateo, and Sterling, 2013) and organizational leaders need to understand whether HR practices uniformly influence different types of employees.

\section{HR practice bundles and the employment relationship}

Many SHRM studies have tested the effects of a single continuum reflecting the presence or absence of various HR practices (e.g., Chadwick et al., 2013; Takeuchi et al., 2007). However, other studies highlight the merits of bundling HR practices into different conceptual groupings (e.g., Gooderham, Parry, and Ringdal, 2008; Lepak and Snell, 1999). For instance, not all HR practices affect firm-level outcomes equally, nor do employees respond to different HR practices 
in the same ways (e.g., Jiang et al., 2012). We adopted two HR-practice bundles conceptualized by Tsui et al. (1997) and subsequently applied by others to test hypotheses grounded in exchange theory (Shaw, Dineen, Fang, and Vellella, 2009).

Theory about social and economic exchange suggests that the parties involved in a healthy employment relationship engage in ongoing reciprocal exchanges of tangible and intangible outcomes that fulfill each party's expectations and obligations to the other over time (Blau, 1964; Cropanzano and Mitchell, 2005). The two HR practice bundles on which we focus reflect important currencies of exchange from the perspective of each party involved. The inducement HR practices bundle reflects desired outcomes that employees want from their employer, and comprises HR practices that signal an organization's long-term investments in employee well-being, such as favorable benefits and pay, job security, investments in professional development, fair treatment, and flexible scheduling. A second bundle, performance expectation HR practices, reflects what an employer desires from its employees, and comprises HR practices that incentivize and enhance employee performance, such as pay-for-performance plans, and formal mechanisms to deliver performance feedback and conduct performance appraisals. Researchers have found that inducement HR practices are associated with lower quit rates, whereas performance expectation HR practices are associated with higher quit rates (Batt and Colvin, 2011). Such studies demonstrate that this bundling approach can enhance predictive precision by differentiating between HR practices that reflect investments in employees versus practices that reflect expected performance contributions from employees.

\section{An external contingency: The local, industry-specific unemployment rate}

SHRM researchers assert that the external labor market can shape the effects of HR 
practices on outcomes that ultimately influence organizational performance (Jackson and Schuler, 1995). While individual-level research shows that employees often consider the available employment options before deciding to leave (Hom and Griffeth, 1995), meta-analyses at the organization-level have produced conflicting results. For instance, whereas one study found that regional and industry-specific unemployment rates had negative effects on overall turnover (Carsten and Spector, 1987), other studies report that unemployment rates have little to no effect on overall turnover or quit rates (Heavey, Holwerda, and Hausknecht, 2013). Research is needed to clarify these mixed findings.

Considered in the context of exchange theory, the local unemployment rate shapes the ability of workers to act on any exchange-based desires to leave in the hope of securing a more favorable employment relationship elsewhere. When the local industry-specific unemployment rate is higher, for example, the dearth of job opportunities for disgruntled employees constrains their ability to leave. At the best of times, employees incur meaningful costs (e.g., resources and time) in their effort to secure new employment, and quitting one's job becomes even costlier when the prospect of securing another position is low. We apply this rationale to develop hypotheses about the respective negative and positive effects of inducement and performance expectation HR practices on quit rates.

Inducement HR practices and quit rates. Healthy social exchange relationships are built on a foundation of two-way trust, wherein each party trusts the other to fulfill its obligations in the ongoing exchange of mutual benefits, which are often neither verbalized nor formally defined (Cropanzano and Mitchell, 2005). Inducement HR practices demonstrate an employer's investments in employee well-being (e.g., flexible scheduling and fair treatment), and signal the employer's long-term commitment to the employment relationship (e.g., professional 
development and internal promotion policies). These HR practices reflect the kinds of discretionary organizational actions that enhance employees' perceptions of their employment relationship and motivate them to maintain it (Cropanzano and Mitchell, 2005).

In contrast, a relative lack of inducement HR practices sends signals to employees about their employer's unwillingness to invest in their long-term employment relationship, motivating them to seek a more favorable relationship elsewhere. Indeed, specific inducement practices like favorable pay and benefits have been shown to relate negatively to quit rates (Shaw et al., 1998), as have bundles of inducement HR practices (Batt and Colvin, 2011; Shaw et al., 2009). For many employees, however, their ability to act on their exchange-based motives to leave depends on the availability of local industry-specific employment opportunities that align with their immediate job experience and associated skillset.

Hypothesis 1: The negative effect of inducement HR practices on subsequent quit rates is stronger when the local industry-specific unemployment rate is lower.

Performance expectation HR practices and quit rates. Performance expectation HR practices include providing performance-based feedback and incentives to enhance employee performance. HR practices like these are unlikely to invoke employees' social exchange-based obligations to reciprocate through continued commitment to the employment relationship. This is because, rather than reflecting an employer's efforts to promote long-term employee well-being, these HR practices reflect the employer's attempt to promote its own well-being. In contrast to the link between inducement HR practices and lower quit rates, performance expectation HR practices have been linked to higher quit rates (Batt and Colvin, 2011; Shaw et al., 1998).

Compared to the strength of the negative effect of inducement HR practices specified in Hypothesis 1, we expect the positive effect of performance expectation HR practices on quit 
rates to be weaker. Some employees largely view their employment relationship in transactional terms that focus on economic exchange (e.g., Stamper and Van Dyne, 2001), and performance expectation HR practices can motivate some portion of them to stay in the hope of reaping performance-based financial rewards. Given that performance expectation HR practices tend to motivate employees to leave while motivating a smaller portion of them to stay, these practices exert a relatively weak positive effect on quit rates, which becomes even weaker when employees' ability to leave is constrained by a lack of available employment options.

\section{Hypothesis 2: The positive effect of performance expectation HR practices on} subsequent quit rates is stronger when the local industry-specific unemployment rate is lower.

\section{An internal contingency: Employees' full-time, part-time, and temporary status}

In the HR and SHRM literatures, researchers have tacitly treated temporary workers, PT employees, and FT employees as a homogeneous group (Cappelli and Keller, 2012). However, workers in different employment arrangements likely differ in the psychological contract expectations of their employer and in how they view their employment relationship (e.g., Gakovic and Tetrick, 2003). The literatures on different employment modes, however, have yet to reach mature stages of development, some of which have been criticized for being atheoretical and replete with contradictory findings (De Cuyper et al., 2008a). In response to calls for research on the effects of HR practices among workers in different employment modes (Conway and Briner, 2002; Feldman and Doerpinghaus, 1992), we tested hypotheses about the relative effects of HR practices on quit rates between FT, PT, and temporary employees.

Some researchers have derived propositions from exchange theory to explain differences between FT and PT employees. FT employees spend a substantial amount of time at work, have 
many opportunities to develop relationships with their coworkers and managers, and they are often focused on longer-term career advancement and personal development (Feldman, 1995). To FT employees, organizational membership represents a salient aspect of their identity (Conway and Briner, 2002). As such, FT employees tend to emphasize the quality of their longterm and mutually beneficial social exchange relationship with their employer.

Compared to FT employees, PT employees may be more focused on an economic exchange relationship and less concerened about the quality of social exchanges with their employer. PT workers have been found to have weaker relational-based obligations to their employers (Gakovick and Tetrick, 2003), and they engage in less citizenship behavior than do FT employees (Conway and Briner, 2002; Stamper and van Dyne, 2001). Because PT employees are less involved in the organization's social milieu, they likely place more emphasis on transactional exchanges of performance contributions in return for contractually-specified compensation (Gakovick and Tetrick, 2003).

Given these arguments, FT employees tend to be more focused on the quality of social exchanges with their employer, whereas PT employees are more focused on the transactional aspects of their exchange relationship. As such, inducement HR practices - which are indicative of longer-term employee investments and the intent to foster a mutually beneficial employment relationship - have a relatively stronger effect on reducing quit rates among FT compared to PT employees.

Performance expectation HR practices can provide employees with favorable economic outcomes in exchange for high performance. Consistent with the rationale for Hypothesis 2, such HR systems may violate the social exchange expectations of FT workers, increasing quit rates among this group. Alternatively, as compared to FT employees, PT workers likely possess 
relatively lower expectations of social exchanges, and higher expectations of transactional exchanges. PT employees may not perceive performance expectation practices as a serious violation of their exchange expectations; thus, the effect of this HR bundle is likely to have a weaker effect on the quit rates of PT compared to FT employees.

In addition to differences between FT and PT employees, the permanence of the employment relationship may also influence workers' exchange expectations. Of note, some previous research on differences in exchange expectations between FT and PT employees did not specify whether employees were temporary or permanent. Given that many PT employees tend to have shorter tenure with their employer than do FT workers (Stamper and Van Dyne, 2001), the temporary and PT status of the employees in these studies may have been confounded. This underscores the importance of testing the extent to which HR practices produce different effects on the quit rates among permanent FT, permanent PT, and temporary employees.

Temporary workers, we suggest, tend to conceptualize their employment relationship more like PT employees, but they are apt to place even greater emphasis on a transactional view of their employment relationship compared to PT employees. Research has found that temporary workers tend to focus on economic exchanges and have lower expectations about social exchanges with their employers compared to their more permanent counterparts (De Cuyper, Rigotti, De Witte, and Mohr, 2008b). Temporary workers’ psychological contract expectations also appear to be considerably more modest than the expectations of permanent employees (Guest, 2004). Consistent with having a relatively weaker emphasis on their social exchange relationship with their employer, Scheel, Rigotti, and Mohr (2013) found evidence that temporary workers were generally less sensitive to incongruence in the training programs offered to different employee groups than were permanent employees. 
The above evidence suggests that temporary employees have relatively limited social exchange expectations of their employers, and they focus more on the favorability of transactional exchanges. In contrast to permanent FT and PT employees, temporary employment arrangements may be too short for a balanced social exchange relationship to develop (Connelly and Gallagher, 2004). Also differentiating temporary workers from PT employees is that PT work is desirable for some employees (Stamper and Van Dyne, 2001), and a PT work arrangement itself may be an inducement for those who do not wish to work FT hours. Some PT employees may experience a strong relational obligation to their employer who made the work arrangement possible, which may foster a relatively greater focus on their long-term social exchange relationships that temporary workers are unlikely to experience.

To summarize the arguments above, permanent FT employees are likely to have the highest expectations about the quality of their social exchange relationship, followed by permanent PT employees, and then temporary workers. In contrast, temporary employees are likely to have the highest transactional exchange expectations, followed by permanent PT and permanent FT employees, respectively. Accordingly, we tested the following hypotheses:

Hypothesis 3: The negative effect of inducement HR practices on quit rates will be strongest among permanent FT employees, followed by permanent PT employees, and weakest among temporary workers.

Hypothesis 4: The positive effect of performance expectation HR practices on quit rates will be strongest among permanent FT employees, followed by permanent PT employees, and weakest among temporary workers.

Hypotheses 1 and 2 were about how an external contingency - the local industryspecific unemployment rate-shapes the effects of HR practices on quit rates. As per the 
rationale for those hypotheses, we expect all of the HR practice effects on quit rates among FT employees, PT employees, and temporary workers to be stronger when the labor market affords people more alternative employment opportunities.

\section{Method}

\section{Sample and procedure}

We collected data via two biennial national surveys of compensation practices in the Canadian Travel, Tourism, and Hospitality industry sponsored by the Canadian Tourism Human Resource Council. A consulting firm administered the first survey between September 2008 and January 2009 to collect data about the 2007 year, and the second survey between September 2010 and January 2011 to collect data about the 2009 year. To reduce concerns about reverse causality, we examined the effects of 2007 HR practices on 2009 quit rates, while controlling for overall turnover rates in 2007.

We collected survey responses from senior-level representatives (i.e., an HR manager, operational manager, or business owner) of each establishment, which included owner-operated independent businesses, owner-operated franchise locations, or independently managed subsidiaries and branches. To enhance sample representativeness, we collected data from establishments located in all Canadian provinces and classified within four industry subsectors: Food and Beverage, Accommodation, Recreation and Entertainment, and Travel Services. Of the 2,016 representatives who responded to the first survey, 673 provided data about HR practices and overall turnover rates. Of the 1,961 representatives who responded to the second survey, 667 provided quit rate data for FT employees, 533 provided quit rates for PT employees, and 441 provided it for temporary seasonal employees. We obtained data from both surveys for 1,036 establishments. Tests of Hypotheses 1 and 2 were based on data from organizations that provided 
quit rates for any employee group, and this sample contained 292 establishments. To test Hypotheses 3 and 4 we constrained the samples to establishments that provided data for both FT and PT workers, or temporary and permanent workers to reduce the potential influence of unobserved effects associated with different employment structures. The final samples for these tests comprised 257 establishments who reported quit rates for both FT and PT employees and 171 establishments who provided data for both permanent and temporary employees. The wording of all survey items reflected the establishment-level of analysis.

\section{Measures}

HR practice bundles. Measures of HR practice bundles were developed based on theory and existing measures (Shaw et al., 1998; Tsui et al., 1997), and in consultation with industry stakeholders who suggested some of the wording of items and response options described below. We measured each bundle as an additive index, calculated from responses to the first survey about the 2007 HR practices used in each establishment. The rationale for creating additive indices is that the different HR practices within a bundle are conceptualized as substitutable means of achieving the same broader objective (Batt and Colvin, 2011; Shaw et al., 2009). As such, we did not conceptualize the bundles as reflective measures for which the items are assumed to be caused by an underlying latent factor, thereby making the items 'hang together'. In contrast, the HR practice bundles are formative measures for which the indicators are conceptualized as causes of the composite (Diamantopoulos and Siguaw, 2006). We make no claims about the presence of underlying latent constructs or covariance among the HR practices within each bundle, and we note that internal consistency is not an appropriate indicator of the efficacy of these measures. Following prior measurement practice (Batt and Colvin, 2011; Shaw et al., 2009), we gave equal weighting to each HR practice included in a given bundle by 
computing an average among the z-scores for each HR practice.

Inducement HR practices. The inducement bundle comprised eight HR practices. Three HR practices were measured using responses on a scale from 1 (no investment) to 4 (significant investment) to items about internal promotion ("Filling open jobs internally before recruiting outside the company"), involvement in the business ("Showing employees how their job contributes to the business"), and fairness (for businesses with fewer than 20 employees, "Treating all employees fairly"; and for larger businesses, "Training managers to treat employees fairly"). The other five HR practices were measured by averaging affirmative responses to the associated questions about the presence of 15 benefits: flexible scheduling (flex time, job sharing, and telecommuting), health and insurance (supplementary health coverage, short-term and long-term disability insurance, and life insurance), professional development (job-relevant training and paid professional association memberships), perquisites (merchandise discounts, fitness memberships, event tickets, and company car/mileage coverage), and supplementary compensation (paid parental leave beyond legislated requirements and registered retirement savings plan contributions).

Performance expectation HR practices. We measured the performance expectation bundle by averaging three standardized scores. Two scores were based on responses from 1 (no investment) to 4 (significant investment) about performance-based incentives ("Creating a clear link between job performance and rewards") and performance feedback (“Giving employees clear, constructive, and regular feedback"). The third standardized score reflected the proportion of employees eligible for performance-based bonuses.

Unemployment rate. We collected 2009 unemployment rate data from the Statistics Canada database. Specific unemployment rates were identified in accordance with each 
establishment's industry subsector and province.

Quit rates. We asked respondents to provide the numbers of permanent FT, permanent PT, and temporary workers employed in their establishment in 2009 , and the numbers in each group who quit that same year (counting quits for temporary workers if they voluntarily left before their official end date). We used these data to calculate the overall quit rate among the workforce to test Hypotheses 1 and 2, as well as separate quit rates specific to FT, PT, and temporary employees to test Hypotheses 3 and 4.

Control variables. We grouped establishments by industry subsector and province, and conducted multilevel modeling allowing the intercepts to vary randomly across groups. To control for the effects of industry subsector on turnover, we entered three dummy variables for the Food and Beverage, Accommodation, and Recreation and Entertainment subsectors (the Travel Services subsector was the baseline). We also entered three dummy variables for regionone for the Western Canadian provinces, one for Ontario, and one for Quebec (the maritime provinces in Eastern Canada were the baseline) — because there were different economic conditions between regions in Canada at the time of the study. ${ }^{1}$ We controlled for establishment size using the natural logarithm of total employees because larger establishments may have more sophisticated HR systems. We controlled for unionization rates because unionized employees may experience more inducement HR practices and unionization can influence turnover (Heavey et al., 2013). We were unable to obtain prior quit rate data, but we did obtain and control for 2007 overall turnover rates (i.e., including quits and dismissals) in the tests of Hypotheses 1 and

\footnotetext{
${ }^{1}$ The level 2 groups were derived from industry subsector and province - inserting dummy variables for these constructs reduced the between-group variance in intercepts, but not slopes, in the multilevel model. We included these dummies because they allowed us to estimate the main effects of region and industry subsector and also estimate a source of between-group slope variance (i.e., unemployment rates), which was the focus of Hypotheses 1 and 2.
} 
2. To test Hypotheses 3 and 4, we controlled for the natural log transformed quit rate of the other employee groups in the organization. For example, we controlled for permanent employee quit rates when testing the effects of HR practices on quit rates for temporary employees. This approach allowed us to isolate the effects of HR practices on the quit rates of each employee group while accounting for organization-level factors that may have influenced the quit rates of

all employees. We were unable to control for the lagged overall turnover variable to examine Hypotheses 3 and 4 because there were linear dependencies between the lagged turnover rate and some of the other employee group quit rates, which prevented some of the models from converging.

\section{Analytic approach}

To analyze the multilevel data, the establishments were clustered by province and industry subsector, and we entered the unemployment rates at this level. The sample size of level 2 units ranged from 36 to 38 , depending on the employee group. Because the quit rate variables were not normally distributed and censored at zero $(16.25 \%$ of the establishments reported zero quits), we applied a generalized linear modeling approach and modeled the number of quits as count variables. The count distributions were overdispersed, so we conducted negative binomial regression analysis (Gelman and Hill, 2007) using MPlus 7.2. We log-transformed the total number of employees in the organization and for each employee group within the organization, and entered these as offset variables to account for the likelihood that the number of quits increased as a function of establishment size. We entered the dummy variables, establishment size, unionization rate, and HR bundles as predictors in the level-1 equations. Per Hofmann and Gavin (1998), we used grand-mean centering when examining main effects at level 1 while controlling for level-2 variables, and we used group-mean centering when testing cross-level 
interactions.

\section{Results}

Table 1 shows the means, standard deviations, and correlations among level 1 study variables, and Table 2 presents the results of hypothesis testing. Hypothesis 1 stated that the negative effect of inducement HR practices on total quit rates is stronger when the unemployment rate is lower. Table 2 shows that the associated interaction was significant, so we applied Preacher, Curran, and Bauer's (2006) approach to probe this cross-level interaction. Supporting Hypothesis 1, and as displayed in Figure 1, the negative effect of inducement HR practices on quit rates was significant when unemployment rates were one SD below the mean $(\gamma$ $=-.65, p=.002)$ but not significant at one SD above the mean $(\gamma=-.04, p=.859)$. Hypothesis 2 was not supported, as Table 2 shows that the interaction between performance expectation practices and unemployment rates was not statistically significant.

Hypothesis 3 stated that inducement HR practices would have stronger negative effects on quit rates for permanent FT employees, followed by permanent PT employees and temporary workers, respectively. As displayed in the Model 1 columns of Table 3, inducement practices had a significant negative effect on the quit rates of FT employees and PT employees, and the effect was positive but not statistically significant among temporary employees. The difference in effect sizes was not significant between FT and PT employees $(z=1.01, p=.312)$, but the effect on temporary employee quits was significantly different from both FT $(z=2.37, p=.018)$ and PT employees $(z=3.21, p<.001)$. Thus, Hypothesis 3 was partially supported.

Hypotheses 4 stated that performance expectation HR practices would have the strongest positive effect on quit rates among permanent FT employees, followed by permanent PT employees, and temporary employees, respectively. Table 3 shows that this hypothesis was not 
supported, as the main effects were not significant for any of the employee groups, nor were any effect sizes significantly different between employee groups.

We also expected the effects of the HR bundles on quit rates in each employee group to be contingent on the local industry-specific unemployment rates. Table 3 shows the significant cross-level interactions between unemployment rate and inducement HR practices on both FT and PT quit rates. Figure 2 displays the interaction effects for FT employees; the effect of inducements on quits rates was not significant when unemployment rates were higher $(\gamma=-.19, p$ $=.444)$, but the effect was significant for lower unemployment $(\gamma=-.69, p=.005)$. There was a similar pattern for PT employees where the effect was stronger in conditions of lower $(\gamma=-.95, p$ $<.001)$ versus higher $(\gamma=-.47, p=.012)$ unemployment (see Figure 3).

There was a very different pattern of interactions for temporary employees. The interaction between inducements and unemployment rate did not have a significant effect on temporary employee quit rates. However, the interaction between performance expectation HR practices and unemployment rate was significant. As displayed in Figure 4, the effect of performance expectation HR practices on temporary employee quits was negative when unemployment rates were higher $(\gamma=-.54, p<.001)$ and not significant when unemployment rates were lower $(\gamma=.42, p=.074)$.

\section{Discussion}

Using lagged data from over 200 establishments in the Canadian Travel, Tourism, and Hospitality industry, we tested hypotheses grounded in exchange theory about internal and external contingencies that shape the effects of different bundles of HR practices on employees' subsequent quit rates. The two HR practice bundles we tested reflect important exchange-based considerations in employees' decision to leave: their employer's investments in employee well- 
being and long-term employment relationships (i.e., inducement HR practices), and their employer's performance demands and the financial rewards they can obtain from meeting them (i.e., performance expectation HR practices). The two contingencies we assessed also pertain to employees' exchange-based decisions to leave: their ability to secure a more favorable exchange relationship elsewhere (i.e., local industry-specific unemployment rates), and whether they view their existing employment relationship in more relational or transactional terms as a function of their employment status (comparing permanent FT employees, permanent PT employees, and temporary workers).

Results pertaining to Hypotheses 1 and 2 showed that when the local industry-specific labor market provided greater opportunities for employee mobility, inducement HR practices were associated with lower quit rates. However, we found no such effect when unemployment rates were higher. The pattern of simple slopes in this interaction effect conforms to the rationale for Hypothesis 1 . When employees face fewer constraints that would otherwise challenge their ability to leave, our findings suggest that a relative absence of inducement HR practices signals their employer's unwillingness to invest in their well-being and long-term employment, which motivates employees to seek a more favorable relationship elsewhere. In this same context, higher levels of inducement HR practices demonstrate the employer's discretionary long-term investments to enhance employees' well-being, which motivates them to maintain their commitment to the employment relationship. However, in contexts where there are few alternative employment opportunities, the employer's inducement HR practices have little effect on employees' quitting behavior.

Other findings showed little support for the expected positive effect of performance expectation HR practices on employee quit rates, nor was this relationship moderated by 
unemployment rates. Findings from Shaw et al. (2009) might explain these null effects: whereas performance expectation HR practices appeared to reduce quits among higher performing employees who stood to benefit from the receipt of performance-based rewards, these same HR practices increased quits among lower performing employees who presumably had little chance of receiving such financial rewards. Thus, the existence of both positive and negative effects due to unmeasured variability in employee performance may have "canceled each other out" and resulted in the null effects observed in this study.

We also tested hypotheses about the main and interactive effects of the HR practice bundles on quit rates in the context of an internal contingency: employees' status as FT, PT, or temporary workers. These employment structures may affect employees' expectations about their employment relationship and ultimately shape the effects of HR practices on subsequent quit rates. The tests of Hypothesis 3 showed that inducement HR practices were associated with lower quit rates among FT employees who, theory suggests, tend to focus on the quality of their long-term social exchange relationship. We found a similar effect among PT employees, suggesting that permanent FT and PT employees have similar levels of concern for their employer's investments in the social exchange relationship.

We found a markedly different pattern of results for temporary employees. In contrast to the negative effects of inducement HR practices on quit rates among FT and PT employees, we found no such effect among temporary workers, suggesting that they place little emphasis on the longer-term social exchange relationship with their employer. Moreover, among FT and PT employees, performance expectation HR practices had no effect on quit rates. Among temporary workers, in contrast, we found they were less likely to quit when both performance expectation HR practices and unemployment rates were high. This latter finding suggests that temporary 
workers tend to emphasize their economic exchange relationship with their employer, as they are motivated to maximize earnings during their shorter employment term given their more uncertain future employment prospects. As such, temporary employees are apt to stay with an employer that offers more opportunities to earn supplemental income (bonuses), particularly when few alternative employment opportunities are available. Considered together, the results point to an intriguing conclusion. It appears that employees' exchange-based decisions to leave may be affected less by the number of hours they expect to work each week compared to the number of weeks they expect to work.

\section{Study findings in context}

Temporary working arrangements and flexible relationships between organizations and their employees are becoming increasingly common (Bidwell et al., 2013; OECD, 2014), and therefore our findings are an important part of understanding the implications of different employment modes on individual and organizational outcomes. We also considered the generalizability of study findings based on data collected from Canadian establishments, and the potential implications of collecting study data in the midst of the global recession. While a full description of our assessments are beyond the scope of this article, evidence suggests that the recession had relatively little bearing on the employment context within the Canadian Travel, Tourism, and Hospitality industry. Relative to the United States, the strength and duration of the economic recession and resulting employment losses were considerably less pronounced in Canada, where many job losses in the first half of 2008 were offset by gains during the second half (LaRochelle-Cote and Gilmore, 2009). Furthermore, the majority of Canadian employment losses occurred in industries other than that on which we focused, and the relevant period of 
increased unemployment rates had comparable effects on FT versus PT workers, for which the rates differed by $0.6 \%$ (LaRochelle-Cote and Gilmore, 2009).

According to the US Bureau of Labor Statistics (BLS, 2013), the pre-recession 2007 unemployment rate in Canada was 5.2\%, a rate comparable to the US (4.6\%), UK (5.4\%), and Sweden $(6.1 \%)$, for example. By 2009, the Canadian unemployment rate increased by $2.1 \%$, which was comparable to the increases observed in other countries, such as the UK (2.2\%), Sweden (2.2\%), New Zealand (2.4\%), France (1.1\%) and Japan (1.2\%); in contrast, the increase in the US during this same period was $4.7 \%$, which is more comparable to the increase observed in Turkey (3.8\%), for example (BLS, 2013). Thus, the changes in unemployment rates in Canada appear generally consistent with changes observed in several other countries during the same period, suggesting that our findings are unlikely to be idiosyncratic to the Canadian context. In addition, the ratio of FT to PT workers in Canada was comparable in 2007 (4.46:1) and 2009 (4.19:1), and has undergone little change according to more recent 2013 data (4.30:1; OECD, 2014). This 2013 ratio is similar to the ratio in Italy (4.59), France (4.46), and the US (4.21). Given the similar distributions of employment modes, our findings may be generalizable to the US and several European countries. Moreover, our results show that inducement HR practices are linked to PT employee quit rates, so our findings may have even greater implications for countries with larger proportions of PT workers, such as the Netherlands (1.75), Australia (2.32), and the UK (2.79).

\section{Implications for research and practice}

Our results are consistent with individual-level turnover research and exchange theory (e.g., Hom and Griffeth, 1995), suggesting that when employees perceive inadequate contributions from their employer with respect to their social exchange relationship, they 
rationally evaluate the availability of alternative employment before deciding to quit. Research is needed to better integrate SHRM and turnover theories to determine how employees evaluate HR practices at each stage of the turnover decision-making process. Much of the research in the applied psychology and management literatures on antecedents to voluntary turnover has focused on employee attitudes (Russell, 2013), and our findings about interactive effects between HR practices and conditions in the external labor market reinforce the need for research that extends beyond the focus on attitudinal antecedents.

Our study provides evidence that differentiating between bundles of HR practices is useful for understanding the effects of HR practices on employee outcomes. In future studies, scholars should continue to examine the construct domain of each conceptualized bundle. For example, other researchers included "employee monitoring" in their performance expectations bundle (Batt and Colvin, 2011; Shaw et al., 2009), which may partly explain why our findings are somewhat different from theirs. The inclusion of employee monitoring was relevant for their samples - employees in the trucking industry and in call centers - but may not generalize to other job contexts.

Our findings also highlight the value of examining the effects of HR practices on different types of employee groups, rather than treating all employees as a single group with homogenous perceptions and reactions. Future research should distinguish between employees with different types of employment relationships-FT and PT is one way to examine these differences, but our findings suggest that a more important distinction is between permanent versus temporary workers who appear to respond differently to different HR practices. Additionally, although we noted above that prior research has focused largely on attitudes, differences in attitudes between these employee groups has not been extensively explored and 
may be a useful avenue for future research in order to more fully understand the effects of HR practices between different employee groups.

To the extent our findings reflect causal relationships, this study suggests firms can benefit from investing in inducement HR practices among their core workforce: for every one unit increase in these HR practices, quit rates decreased by $34 \%$ and $51 \%$ among FT and PT employees, respectively. Managers should avoid treating permanent PT employees as 'second class citizens,' as inducement HR practices that signal the employer's investments in the social exchange relationship appear to matter to PT employees as much as they do to FT employees.

Our findings also suggest that organizations should be attentive to the external labor market as a key boundary condition that shapes voluntary turnover behavior. Moreover, for larger organizations with multiple establishments, our study suggests that HR systems may function differently in different labor markets. Having a healthy social exchange relationship with an employer appears to be important to both FT and PT members of the workforce, and investing in those relationships when unemployment is higher can signal the firm's long-term commitment to its employees, which may ultimately prove beneficial when labor market conditions change.

\section{Limitations}

We collected data from a nation-wide sample of HR professionals and firm representatives and this contributed to the validity of our study. However, a potential limitation is that the same rater from each establishment assessed most study variables, so same-source variance may have influenced our results. Notably, however, the differential and theoreticallyconsistent pattern of results for the two HR practice bundles, and the two year lag between measurement of the predictor and criterion variables, suggests that same-source bias did not 
overly influence our findings. Moreover, we obtained unemployment rates from an independent database and the measures of benefits and quit rates were based on more objective metrics, and thus, were less likely to suffer from same-source bias. Another limitation is the possibility that our results involving HR practice bundles may reflect spurious effects because the respondents focused on all employees when completing the surveys even though managers may apply HR practices differently to FT, PT, and temporary employees. Indeed, there were modest but significant correlations between the proportion of FT employees in the workforce and inducement HR practices $(r=.23, p<.001)$ and between the proportion of temporary employees and inducement HR practices $(r=-.17, p=.007)$. To check the robustness of the findings, we reanalyzed the models with the temporary employee quit rate outcome only for organizations where temporary employees consisted of at least $50 \%$ of the workforce, because it is more likely that the reported HR systems applied to temporary employees in these organizations. The pattern of main effects for the HR bundles from this analysis was consistent with the results from the full sample $(\gamma=.42, p=.326$ and $\gamma=.09, p=.672$ for effects of inducement HR practices and performance expectation HR practices, respectively). Although the interaction between performance expectations and unemployment rate was not significant in this analysis $(\gamma=-.17, p$ $=.222$ ), the strength and direction of the effect was similar to that reported in the full sample. The substantially smaller sample size in the robustness check (Level $1 n=75$, Level $2 n=24$ ) reduced the power to detect statistically significant effects. These results provide some confidence that the observed effects were not simply a result of different employee groups who were subject to different HR systems. Finally, it is possible that both firms and employee groups may systematically differ in unmeasured ways (e.g., firm performance, gender composition) that might influence the effects of HR practices on quit rates. 


\section{Conclusions}

SHRM scholars continue to call for greater alignment between research and practice in the field. For instance, researchers emphasize the need to develop theory and delineate the mechanisms through which management practices influence operational outcomes, and have called on others to study variables that practitioners can pragmatically control (Becker and Huselid, 2006). Other scholars have appealed to practitioners to master the theory underlying their methods so they can understand the types of practices that will be effective in different situations (Bowen and Ostroff, 2004). We believe this study helped accomplish both objectives by contributing to theory development through clarifying the differential effects of specific HR practices that practitioners can control, their impact on important quit rate outcomes, and the external conditions under which these HR practices have a stronger or weaker impact. 
Contingent Effects of HR Practices on Voluntary Turnover 28

\section{References}

Batt, R., and Colvin, A. J. (2011), 'An employment systems approach to turnover: Human resources practices, quits, dismissals, and performance', Academy of Management Journal, 54, 696-717.

Becker, B. E., and Huselid, M. A. (2006), 'Strategic human resources management: Where do we go from here?', Journal of Management, 32, 898-925.

Bidwell, M., Briscoe, F., Fernandez-Mateo, I., and Sterling, A. (2013), 'The employment relationship and inequality: how and why changes in employment practices are reshaping rewards in organizations', The Academy of Management Annals, 7, 61-121.

Blau, P. M. (1964), Exchange and power in social life, New York: Wiley.

Bowen, D. E., and Ostroff, C. (2004), 'Understanding HRM-firm performance linkages: The role of the "strength" of the HRM system', Academy of Management Review, 29, 203-221.

Boxall, P., and Purcell, J. (2000), 'Strategic human resource management: Where have we come from and where should we be going?', International Journal of Management Reviews, 2, 183-203.

Cappelli, P., and Keller, J. (2012), 'Classifying work in the new economy', Academy of Management Review, 38, 575-596.

Carsten, J. M., and Spector, P. E. (1987), 'Unemployment, job satisfaction, and employee turnover: A meta-analytic test of the Muchinsky model', Journal of Applied Psychology, 72, 374-381.

Chadwick, C., Way, S. A., Kerr, G., and Thacker, J. W. (2013), 'Boundary conditions of the high-investment human resource systems-small-firm labor productivity relationship', Personnel Psychology, 66, 311-343.

Connelly, C. E., and Gallagher, D. G. (2004), 'Emerging trends in contingent work research', Journal of Management, 30, 959-983.

Conway, N., and Briner, R. B. (2002), 'Full-time versus part-time employees: Understanding the 
links between work status, the psychological contract, and attitudes', Journal of Vocational Behavior, 61, 279-301.

Crook, T., Todd, S. Y., Combs, J. G., Woehr, D. J., and Ketchen, D. J., Jr. (2011), 'Does human capital matter? A meta-analysis of the relationship between human capital and firm performance', Journal of Applied Psychology, 96, 443-456.

Cropanzano, R., and Mitchell, M. S. (2005), 'Social exchange theory: An interdisciplinary review', Journal of Management, 31, 874-900.

De Cuyper, N., de Jong, J., De Witte, H., Isaksson, K., Rigotti, T., and Schalk, R. (2008a), 'Literature review of theory and research on the psychological impact of temporary employment: Towards a conceptual model', International Journal of Management Reviews, $10,25-51$.

De Cuyper, N., Rigotti, T., De Witte, H., and Mohr, G. (2008b), 'Balancing psychological contracts: Validation of a typology', International Journal of Human Resource Management, 19, 543-561.

Diamantopoulos, A., and Siguaw, J. A. (2006), 'Formative versus reflective indicators in organizational measure development: A comparison and empirical illustration', British Journal of Management, 17, 263-282.

Feldman, D. C. (1995), 'Managing part-time and temporary employment relationships: Individual needs and organizational demands', in M. E. London (ed), Employees, Careers, and Job Creation: Developing Growth-Oriented Human Resource Strategies and Programs, San Francisco: Jossey-Bass.

Feldman, D. C., and Doerpinghaus, H. I. (1992), 'Missing persons no longer: Managing parttime workers in the 90s', Organizational Dynamics, 21, 59-72.

Gakovic, A., and Tetrick, L. E. (2003), 'Perceived organization support and work status: A 
comparison of the employment relationships of part-time and full-time employees attending university classes', Journal of Organizational Behavior, 24, 649-666.

Gelman, A., and Hill, J. (2007), Data Analysis Using Regression and Multilevel/Hierarchical Models, New York: Cambridge University Press.

Gooderham, P., Parry, E., and Ringdal, K. (2008), 'The impact of bundles of strategic human resource management practices on the performance of European firms', International Journal of HRM, 19(11), 2041-2056.

Guest, D. (2004), 'Flexible employment contracts, the psychological contract and employee outcomes: an analysis and review of the evidence', International Journal of Management Reviews, 5, 1-19.

Heavey, A. L., Holwerda, J. A., and Hausknecht, J. P. (2013), 'Causes and consequences of collective turnover: A meta-analytic review', Journal of Applied Psychology, 98, 412-453.

Hofmann, D. A., and Gavin, M. B. (1998), 'Centering decisions in hierarchical linear models: Implications for research in organizations', Journal of Management, 24, 623-641.

Hom, P. W., and Griffeth, R. W. (1995), Employee Turnover, Cincinnati, OH: South-Western.

Huselid, M. A. (1995), 'The impact of human resource management practices on turnover, productivity, and corporate financial performance', Academy of Management Journal, 38, 3, 635-672.

Jackson, S. E., and Schuler, R. S. (1995), 'Understanding human resource management in the contect of organizations and their environments', Annual Review of Psychology, 46, 237264.

Jiang, K., Lepak, D. P., Hu, J., and Baer, J. C. (2012), 'How does human resource management influence organizational outcomes? A meta-analytic investigation of mediating mechanisms', Academy of Management Journal, 55, 1264-1294.

Kehoe, R. R., and Wright, P. M. (2013), 'The impact of high-performance human resource practices on employees' attitudes and behaviors', Journal of Management, 39, 366-391. 
LaRochelle-Cote, S., and Gilmore, J. (2009), 'Canada's employment downturn', Perspectives, December 2009, 5-12. Statistics Canada.

Lepak, D. P., and Snell, S. A. (1999), 'The human resource architecture: Toward a theory of human capital allocation and development', Academy of Management Review, 24, 31-48.

OECD (2014), 'Data beta', Available at: http://www.oecd.org.

Park, T.-Y., and Shaw, J. D. (2013), 'Turnover rates and organizational performance: A metaanalysis', Journal of Applied Psychology, 98, 268-309.

Pohler, D., and Schmidt, J. A. (2015), 'Does pay-for-performance strain the employment relationship? The effect of manager bonus eligibility on non-management employee turnover', Personnel Psychology. doi: 0.1111/peps.12106.

Posthuma, R. A., Campion, M. C., Masimova, M., and Campion, M. A. (2013), 'A high performance work practices taxonomy: integrating the literature and directing future research', Journal of Management, 39, 1184-1220.

Preacher, K. J., Curran, P. J., and Bauer, D. J. (2006), 'Computational tools for probing interaction effects in multiple linear regression, multilevel modeling, and latent curve analysis', Journal of Educational and Behavioral Statistics, 31, 437-448.

Russell, C. J. (2013), 'Is it time to voluntarily turn over theories of voluntary turnover?' Industrial and Organizational Psychology, 6, 156-173.

Scheel, T. E., Rigotti, T., and Mohr, G. (2013), 'HR practices and their impact on the psychological contracts of temporary and permanent workers', International Journal of Human Resource Management, 24, 285-307.

Shaw, J. D., Delery, J. E., Jenkins, G., and Gupta, N. (1998), 'An organization-level analysis of voluntary and involuntary turnover', Academy of Management Journal, 41, 511-525.

Shaw, J. D., Dineen, B. R., Fang, R., and Vellella, R. F. (2009), 'Employee-organization 
exchange relationships, HRM practices, and quit rates of good and poor performers', Academy of Management Journal, 52, 1016-1033.

Shore, L. M., Coyle-Shapiro, J. A-M., Chen, X., and Tetrick, L. E. (2009), 'Social exchange in work settings: Content, process, and mixed models', Management and Organization Review, 5, 289-302.

Stamper, C. L., and Van Dyne, L. (2001), 'Work status and organizational citizenship behavior: A field study of restaurant employees', Journal of Organizational Behavior, 22, 517-536.

Sun, L., Aryee, S., and Law, K. S. (2007), 'High-performance human resource practices, citizenship behavior, and organizational performance: A relational perspective', Academy of Management Journal, 50, 558-577.

Takeuchi, R., Lepak, D. P., Wang, H., and Takeuchi, K. (2007), 'An empirical examination of the mechanisms mediating between high-performance work systems and the performance of Japanese organizations', Journal of Applied Psychology, 92, 1069-1083.

Tsui, A. S., Pearce, J. L., Porter, L. W., and Tripoli, A. M. (1997), 'Alternative approaches to the employee-organization relationship: Does investment in employees pay off?' Academy of Management Journal, 40, 1089-1121.

US Bureau of Labor Statistics (BLS). (2013). 'International comparisons of annual labor force statistics, 1970-2012', US Bureau of Labor Statistics, June 7, 2013. 
Contingent Effects of HR Practices on Voluntary Turnover 33

Table 1. Means, standard deviations, and correlations for level 1 variables

\begin{tabular}{|c|c|c|c|c|c|c|c|c|c|c|c|c|c|c|c|c|}
\hline & $M$ & $S D$ & 1 & 2 & 3 & 4 & 5 & 6 & 7 & 8 & 9 & 10 & 11 & 12 & 13 & 14 \\
\hline 1. Food \& Beverage Sector & .15 & 0.36 & & & & & & & & & & & & & & \\
\hline 2. Accommodation Sector & .41 & 0.49 & $-.35^{* *}$ & & & & & & & & & & & & & \\
\hline 3. Recreation \& Entertainment Sector & .31 & 0.46 & $-.28^{* *}$ & $-.55^{* *}$ & & & & & & & & & & & & \\
\hline 4. Western Canada & .32 & 0.47 & -.09 & .04 & .06 & & & & & & & & & & & \\
\hline 5. Ontario & .23 & 0.42 & $-.14^{*}$ & .04 & .00 & $-.37^{* *}$ & & & & & & & & & & \\
\hline 6. Quebec & .23 & 0.42 & .03 & .02 & -.09 & $-.37^{* *}$ & $-.30^{* *}$ & & & & & & & & & \\
\hline 7. Number of Employees (ln) & 3.35 & 1.36 & -.09 & $.21^{* *}$ & .04 & .04 & $.15^{* *}$ & -.07 & & & & & & & & \\
\hline 8. Unionization Rate & 0.16 & 0.35 & $-.19^{* *}$ & $.21^{* *}$ & .01 & .05 & -.01 & .08 & $.33^{* *}$ & & & & & & & \\
\hline 9. Prior Overall Turnover & 0.21 & 0.24 & $.14^{*}$ & .06 & -.07 & .02 & .03 & -.03 & $.13^{*}$ & .08 & & & & & & \\
\hline 10. Inducement HR Practices & -0.08 & 0.50 & $.25^{* *}$ & $.16^{* *}$ & $-.11^{*}$ & .02 & $.13^{*}$ & -.05 & $.31^{* *}$ & $.21^{* *}$ & .00 & & & & & \\
\hline 11. Performance Ex. HR Practices & -0.10 & 0.69 & -.03 & .05 & $-.20^{* *}$ & .03 & .06 & $-.20^{* *}$ & .11 & -.09 & .02 & $.48^{* *}$ & & & & \\
\hline 12. Full Time Employee Quit Rate & 0.20 & 0.42 & .05 & $-.14^{*}$ & $.14^{*}$ & .06 & -.04 & .04 & -.03 & -.09 & $.27^{* *}$ & $-.16^{*}$ & -.06 & & & \\
\hline 13. Part Time Employee Quit Rate & 0.40 & 0.98 & .03 & -.06 & $.15^{*}$ & .01 & .07 & -.02 & .08 & -.01 & $.21^{* *}$ & $-.15^{*}$ & -.08 & $.64^{* *}$ & & \\
\hline 14. Temporary Employee Quit Rate & 0.28 & 0.38 & -.15 & .07 & -.01 & -.05 & $.19^{*}$ & .08 & .05 & .03 & .04 & .13 & .01 & -.07 & $.17^{*}$ & \\
\hline 15. Total Employee Quit Rate & 0.29 & 0.59 & .02 & $-.12^{*}$ & $.16^{*}$ & .01 & .07 & -.02 & .03 & -.03 & $.23^{* *}$ & -.11 & -.02 & $.77^{* *}$ & $.90^{* *}$ & $.62^{* *}$ \\
\hline
\end{tabular}

Note: $N=257$ for correlations with Full-time and Part-time Employee Quit Rates, $N=171$ for correlations with Temporary Employee Quit Rates, $N=292$ for the remainder of the correlations. Discrepancies in sample sizes are due to organizational structures as different companies employed different types of workers. $\ln =$ natural logarithm. "Performance Ex. HR Practices" refers to the Performance Expectation HR Practice bundle.

${ }^{*} p<.05,{ }^{* *} p<.01$. 
Table 2. Effects of HR practice bundles and unemployment rate on total quit rates

\begin{tabular}{|c|c|c|c|}
\hline \multirow{2}{*}{ Predictor Variables } & \multicolumn{3}{|c|}{ Total Quit Rates } \\
\hline & Model 1 & Model 2 & Model 3 \\
\hline \multicolumn{4}{|l|}{ Level 1 Variables } \\
\hline$\gamma_{00}:$ Intercept & $-2.49(.32)^{* *}$ & $-2.49(.21)^{* *}$ & $-2.47(.19)^{* *}$ \\
\hline$\gamma_{10}:$ Food \& Beverage sector & $.31(.18)$ & $.40(.22)$ & $.27(.22)$ \\
\hline$\gamma_{20}:$ Accommodation sector & $.19(.17)$ & $.20(.17)$ & $.16(.17)$ \\
\hline$\gamma_{30}:$ Recreation sector & $.80(.19)^{* * *}$ & $.85(.19)^{* * *}$ & $.71(.23)^{* *}$ \\
\hline$\gamma_{40}:$ Western Canada & $.58(.26)^{*}$ & $.59(.15)^{* *}$ & $.56(.16)^{* *}$ \\
\hline$\gamma_{50}:$ Ontario & $.49(.21)^{*}$ & $.47(.09)^{* *}$ & $.49(.09)^{* *}$ \\
\hline$\gamma_{60}:$ Quebec & $.51(.20)^{*}$ & $.50(.10)^{* *}$ & $.46(.11)^{* *}$ \\
\hline$\gamma_{70}:$ Number of Employees $(\ln )$ & $-.08(.05)$ & $-.09(.06)$ & $-.08(.06)$ \\
\hline$\gamma_{80}:$ Unionization Rate & $-.01(.14)$ & $-.01(.05)$ & $-.02(.05)$ \\
\hline$\gamma_{90}:$ Prior Overall Turnover $(\ln )$ & $.26(.06)^{* *}$ & $.25(.06)^{* *}$ & $.26(.06)^{* *}$ \\
\hline$\gamma_{100}:$ Inducement HR Practices & $-.35(.16)^{*}$ & $-.38(.17)^{*}$ & $-.38(.17)^{*}$ \\
\hline$\gamma_{110}:$ Performance Ex. HR Practices & $.14(.13)$ & $.19(.15)$ & $.19(.14)$ \\
\hline Dispersion Parameter & $.74(.12)^{* *}$ & $.73(.12)^{* *}$ & $.74(.12)$ \\
\hline $\begin{array}{l}\text { Level } 2 \text { Variables and Interactions } \\
\gamma_{01}: \text { Unemployment Rate }\end{array}$ & $.05(.03)$ & $.07(.02)^{* *}$ & $.05(.03)$ \\
\hline $\begin{array}{l}\gamma_{101}: \text { Unemployment Rate } x \\
\text { Inducement HR Practices }\end{array}$ & & $.09(.04)^{*}$ & \\
\hline $\begin{array}{l}\gamma_{111} \text { : Unemployment Rate } \mathrm{x} \\
\text { Performance Ex. HR Practices }\end{array}$ & & & $.02(.06)$ \\
\hline \multicolumn{4}{|l|}{ Variance Components } \\
\hline$\tau_{00}$ : Intercept variance & $.00(.00)$ & $.002(.004)$ & $.00(.00)$ \\
\hline$\tau_{100:}$ Slope variance & & $.02(.05)$ & \\
\hline$\tau_{110:}$ Slope variance & & & $.00(.00)$ \\
\hline$\tau_{0101}:$ Intercept-slope covariance & & $-.01(.02)$ & \\
\hline$\tau_{0111}:$ Intercept-slope covariance & & & $.00(.00)$ \\
\hline
\end{tabular}

Note: Level $1 N=292$, and Level $2 N=36$. ln = natural logarithm. "Performance Ex. HR Practices" refers to the Performance Expectation HR Practice bundle. Standard error terms are shown in parentheses.

${ }^{t} p<.10,{ }^{*} p<.05,{ }^{* *} p<.01$ 
Table 3. Effects of HR practice bundles and unemployment rate on full-time, part-time, and temporary quit rates

\begin{tabular}{|c|c|c|c|c|c|c|c|c|c|}
\hline \multirow{2}{*}{ Predictor Variables } & \multicolumn{3}{|c|}{ Full-Time Quit Rates } & \multicolumn{3}{|c|}{ Part-Time Quit Rates } & \multicolumn{3}{|c|}{ Temporary Quit Rates } \\
\hline & Model 1 & Model 2 & Model 3 & Model 1 & Model 2 & Model 3 & Model 1 & Model 2 & Model 3 \\
\hline \multicolumn{10}{|l|}{ Level 1 Variables } \\
\hline$\gamma_{00}:$ Intercept & $-2.15(.35)^{*}$ & $-2.15(.31)^{* * *}$ & $-2.16(.33)^{* *}$ & $-1.76(.80)^{*}$ & $-1.74(.79)^{*}$ & $-1.78(.81)^{*}$ & $-1.48(.52)^{* * *}$ & $-1.45(.45)^{* *}$ & $-1.44(.45)^{* *}$ \\
\hline$\gamma_{10}$ : Food \& Beverage sector & $.77(.32)^{*}$ & $.76(.28)^{* * *}$ & $.80(.26)^{* *}$ & $1.71(.66)^{*}$ & $1.80(.74)^{*}$ & $1.76(.77)^{*}$ & $-.50(.63)$ & $-.70(.66)$ & $-.42(.58)$ \\
\hline$\gamma_{20}:$ Accommodation sector & $.43(.37)$ & $.54(.34)$ & $.40(.35)$ & $1.73(.69)^{*}$ & $1.72(.77)^{*}$ & $1.61(.80)^{*}$ & $.07(.46)$ & $-.20(.47)$ & $.07(.40)$ \\
\hline$\gamma_{30}:$ Recreation sector & $.69(.33)^{*}$ & $.63(.31)^{*}$ & $.61(.34)^{\dagger}$ & $1.78(.68)^{* * *}$ & $1.96(.77)^{*}$ & $1.92(.81)^{*}$ & $.33(.52)$ & $-.09(.54)$ & $.17(.49)$ \\
\hline$\gamma_{40}:$ Western Canada & $.81(.33)^{*}$ & $.70(.28)^{*}$ & $.79(.38)^{*}$ & $-.25(.36)$ & $-.17(.13)$ & $-.07(.13)$ & $.59(.35)^{\dagger}$ & $.47(.35)$ & $.49(.23)^{*}$ \\
\hline$\gamma_{50}:$ Ontario & $.11(.37)$ & $.17(.27)$ & $.18(.39)$ & $-.14(.30)$ & $-.14(.09)$ & $.01(.16)$ & $.95(.28)^{* * *}$ & $.85(.14)^{* * *}$ & $.98(.13)^{* *}$ \\
\hline$\gamma_{60}:$ Quebec & $.59(.32)^{\dagger}$ & $.63(.19)^{* * *}$ & $.61(.30)^{*}$ & $-.24(.28)$ & $-.24(.15)$ & $-.15(.25)$ & $.65(.32)^{*}$ & $.52(.26)^{*}$ & $.64(.29)^{*}$ \\
\hline$\gamma_{70}$ : Number of Employees $(\ln )$ & $-.19(.08)^{*}$ & $-.19(.07)^{* *}$ & $-.18(.09)^{*}$ & $-.02(.10)$ & $-.05(.10)$ & $-.05(.14)$ & $-.14(.10)$ & $-.18(.42)$ & $-.13(.08)$ \\
\hline$\gamma_{80}:$ Unionization Rate & $-.08(.08)$ & $-.07(.08)$ & $-.07(.13)$ & $.06(.07)$ & $.06(.07)$ & $.06(.17)$ & $.07(.13)$ & $.08(.14)$ & $.09(.13)$ \\
\hline$\gamma_{90}:$ Other Employee Turnover (ln) & $.15(.04)^{* * *}$ & $.14(.04)^{* * *}$ & $.15(.04)^{* *}$ & $.21(.05)^{* * *}$ & $.22(.05)^{* * *}$ & $.21(.05)^{* *}$ & $.03(.05)$ & $.03(.08)$ & $.08(.05)$ \\
\hline$\gamma_{100}$ : Inducement HR Practices & $-.42(.21)^{*}$ & $-.45(.21)^{*}$ & $-.41(.21)^{\dagger}$ & $-.72(.21)^{* * *}$ & $-.73(.21)^{* *}$ & $-.57(.24)^{*}$ & $.43(.29)$ & $.14(.24)$ & $.03(.27)$ \\
\hline$\gamma_{110}$ : Performance Ex. HR Practices & $-.08(.11)$ & $-.05(.15)$ & $-.07(.10)$ & $.11(.14)$ & $.15(.17)$ & $.06(.12)$ & $-.03(.20)$ & $.01(.20)$ & $-.10(.20)$ \\
\hline Dispersion Parameter & $.53(.11)^{* *}$ & $.48(.12)^{* * *}$ & $.52(.12)^{* *}$ & $.61(.14)^{* * *}$ & $.61(.15)^{* *}$ & $.61(.16)^{* *}$ & $1.50(.29)^{* *}$ & $1.49(.29)^{* *}$ & $1.47(.30)^{* *}$ \\
\hline $\begin{array}{l}\text { Level } 2 \text { Variables and Interactions } \\
\gamma_{01}: \text { Unemployment Rate }\end{array}$ & \multirow[t]{3}{*}{$.07(.04)^{\dagger}$} & $.04(.04)$ & \multirow[t]{2}{*}{$.05(.07)$} & \multirow[t]{3}{*}{$-.07(.04)^{\dagger}$} & $-.03(.02)$ & $-.03(.02)$ & \multirow[t]{3}{*}{$.07(.07)$} & \multirow{3}{*}{$\begin{array}{l}.02(.09) \\
-.03(.46)\end{array}$} & \multirow[t]{2}{*}{$.05(.07)$} \\
\hline $\begin{array}{l}\gamma_{0101}: \text { Unemployment Rate } \mathrm{x} \\
\text { Inducement HR Practices }\end{array}$ & & $.08(.04)^{*}$ & & & $.07(.03)^{*}$ & & & & \\
\hline $\begin{array}{l}\gamma_{0111}: \text { Unemployment Rate } \mathrm{x} \\
\text { Performance Ex. HR Practices }\end{array}$ & & \multicolumn{2}{|r|}{$.05(.08)$} & & \multicolumn{2}{|r|}{$.07(.10)$} & & & $-.15(.08)^{*}$ \\
\hline $\begin{array}{l}\text { Variance Components } \\
\tau_{00} \text { Intercept variance } \\
\tau_{10 .} \text { Slope variance }\end{array}$ & $.16(.06)^{* *}$ & $\begin{array}{r}.21(.09)^{*} \\
.08(.07)\end{array}$ & $.19(.07)^{* * *}$ & $.00(.00)$ & $\begin{array}{l}.00(.00) \\
.00(.01)\end{array}$ & $.00(.01)$ & $.00(.00)$ & $\begin{array}{l}.00(.01) \\
.05(.14)\end{array}$ & $.00(.00)$ \\
\hline$\tau_{110:}$ Slope variance & & & $.002(.009)$ & & & $.01(.20)$ & & & $.00(.00)$ \\
\hline$\tau_{0100}:$ Intercept-slope covariance & & $-.13(.08)^{\dagger}$ & & & $.00(.01)$ & & & $.01(.19)$ & \\
\hline$\tau_{0110}:$ Intercept-slope covariance & & & $.02(.04)$ & & & $-.01(.05)$ & & & $.00(.00)$ \\
\hline
\end{tabular}

Note: Level $1 N=257$ and Level $2 N=38$ for FT and PT quits. Level $1 N=171$ and Level $2 N=37$ for temporary quits. ln $=$ natural logarithm. "Performance Ex. HR Practices" refers to the Performance Expectation HR Practice bundle. Standard error terms are shown in parentheses. The Other Employee Turnover variable pertained to PT employees in the FT quit rate models, FT employees in the PT quit rate models, and total permanent employees in the temporary quit rate models.

${ }^{\dagger} p<.10,{ }^{*} p<.05,{ }^{* *} p<.01$ 


\section{Figure Captions}

Figure 1. Effects of inducement HR practices on total employee quit rates by lower versus higher local industry-specific unemployment rates.

Figure 2. Effects of inducement HR practices on full-time employee quit rates by lower versus higher local industry-specific unemployment rates.

Figure 3. Effects of inducement HR practices on part-time employee quit rates by lower versus higher local industry-specific unemployment rates.

Figure 4. Effects of performance expectation HR practices on temporary employee quit rates by lower versus higher local industry-specific unemployment rates. 
Strategic HRM and Workforce Contingencies 37

Figure 1

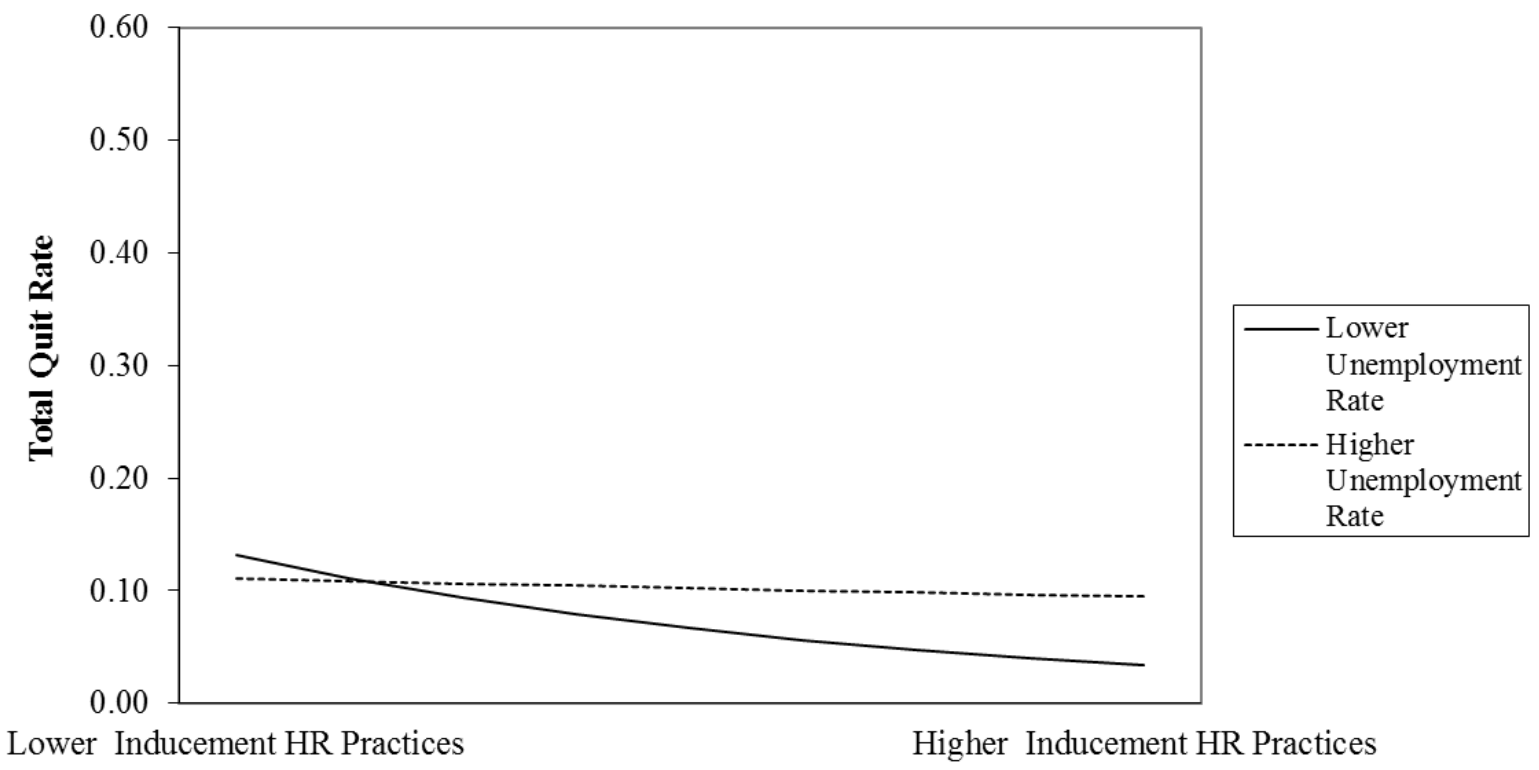


Strategic HRM and Workforce Contingencies 38

Figure 2

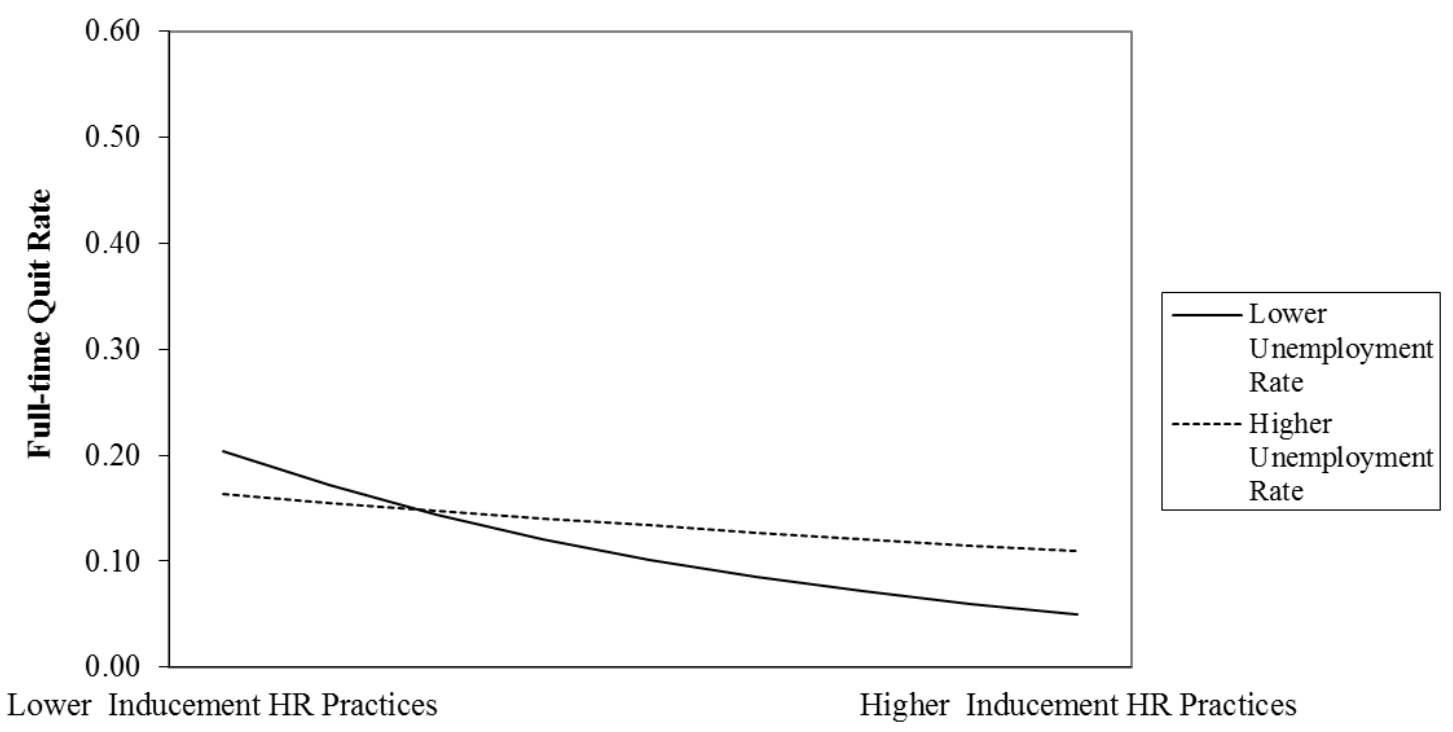




\section{Figure 3}

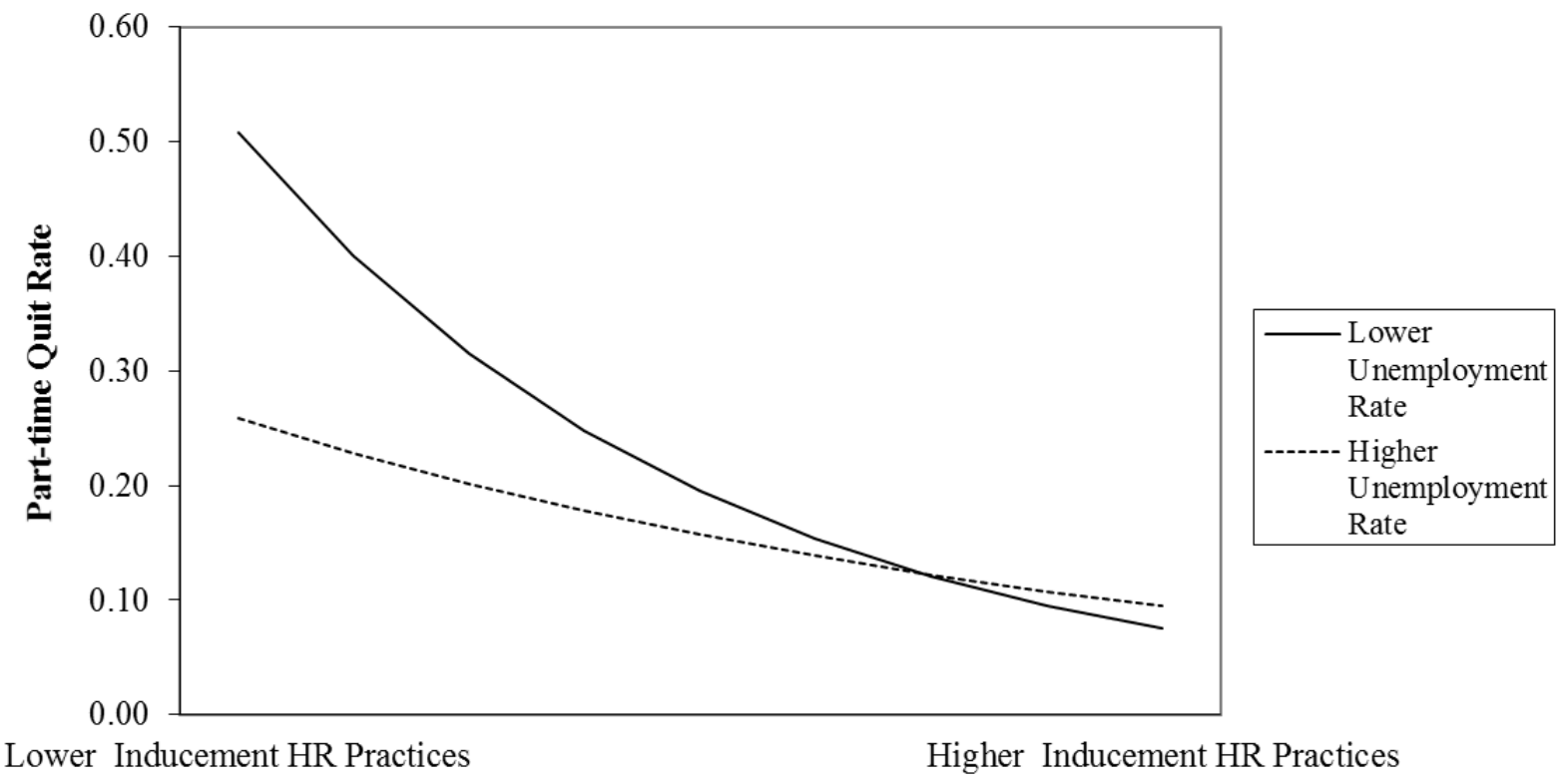


Strategic HRM and Workforce Contingencies 40

Figure 4

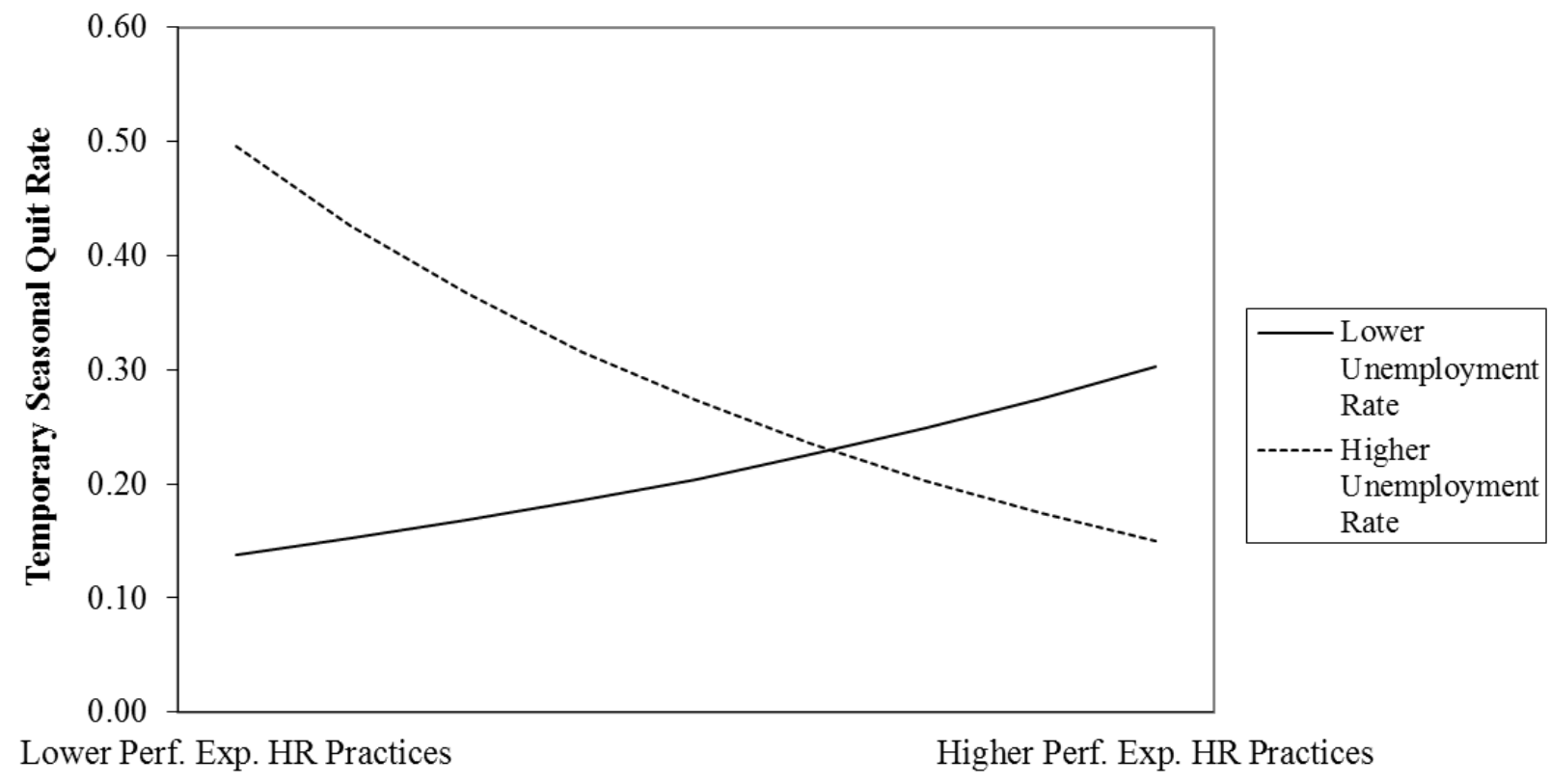

